\title{
Negócios Processuais: uma breve análise sobre os aspectos
}

\author{
Processual Business: a brief analysis on the aspects \\ Negocio Procesal: breve análisis de aspectos
}

Recebido: 11/10/2021 | Revisado: 16/10/2021 | Aceito: 25/10/2021 | Publicado: 28/10/2021

\author{
Heloisa Cristina Luiz Cappellari \\ ORCID: https://orcid.org/0000-0001-5643-9168 \\ Universidade Paranaense, Brasil \\ E-mail: heloluiz@hotmail.com \\ Kamila Rezende \\ ORCID: https://orcid.org/0000-0003-0070-1504 \\ Universidade Paranaense, Brasil \\ E-mail: kamilaarezendee@hotmail.com
}

\begin{abstract}
Resumo
Com o advento do Código de Processo Civil 2015, diversos dispositivos surgiram com a intenção de autorizar que as partes celebrem convenções processuais entre si que vinculem a todos os integrantes de uma relação processual. Dentre eles, toma destaque o artigo 190, que estabelece em sua redação que, em se tratando de direitos disponíveis, as partes podem pactuar sobre questões procedimentais, ônus, poderes, faculdades e deveres processuais, antes ou durante o processo, sujeitos ao controle de validade do juiz e vinculando todos os envolvidos na relação processual. O objetivo do presente trabalho é realizar uma análise sobre os negócios processuais típicos e atípicos, seu cabimento e regramento. A metodologia utilizada foi a analise bibliográfica de doutrina e legislação vigente sobre o assunto. Após a realização da pesquisa, podemos perceber que a intenção do legislador, ao criar tal dispositivo, foi a de prestigiar o princípio da autonomia da vontade das partes, de maneira a alcançar o principal objetivo de uma demanda judicial, que é o de amparar os direitos das partes que procuram o poder judiciário, em detrimento do processualismo religioso, entretanto, a celebração dos negócios processuais, especialmente atípicos, deve ser acompanhada de muito cuidado, considerando que estes não possuem regramento explicito.
\end{abstract}

Palavras-chave: Processo civil; Autonomia; Negócios jurídicos.

\begin{abstract}
With the advent of the Civil Procedure Code 2015, several provisions have emerged with the intention of authorizing the parties to enter into procedural conventions with each other that bind all members of a procedural relationship. Among them, article 190 stands out, which establishes in its wording that, in the case of available rights, the parties may agree on procedural issues, burdens, powers, faculties and procedural duties, before or during the process, subject to the control of validity of the judge and binding all those involved in the procedural relationship. The objective of this work is to carry out an analysis of typical and atypical procedural businesses, their appropriateness and rules. The methodology used was the bibliographic analysis of current doctrine and legislation on the subject. After conducting the survey, we can realize that it is understood that the legislator's intention, when creating such a device, was to honor the principle of autonomy of the parties' will, in order to achieve the main objective of a judicial demand, which is to protect the rights of the parties seeking the judiciary, to the detriment of religious proceduralism. However, the celebration of procedural transactions, especially atypical, must be accompanied with great care, considering that these do not have explicit rules.
\end{abstract}

Keywords: Civil procedure; Autonomy; Procedural business.

\section{Resumen}

Con la llegada del Código de Procedimiento Civil de 2015, surgieron várias disposiciones con la intención de autorizar a las partes a celebrar acuerdos procesales entre ellas que obliguen a todos los miembros de una relación procesal. Entre ellos, se destaca el artículo 190, que establece en su redacción que, en el caso de los derechos disponibles, las partes podrán acordar en cuestiones procesales, carga, atribuciones, facultades y deberes procesales, antes o durante el proceso, sujeto al control de validez del juez y vinculante para todos los involucrados en la relación procesal. El objetivo de este trabajo es realizar un análisis de los negocios procesales típicos y atípicos, su adecuación y normativa. La metodología utilizada fue el análisis bibliográfico de la doctrina y legislación vigente en la materia. Luego de realizar la investigación, podemos ver que la intención del legislador, al crear tal disposición, fue honrar el principio de autonomía de la voluntad de las partes, con el fin de lograr el objetivo principal de un juicio, que es sustentar Los derechos de las partes que buscan el Poder Judicial, en detrimento del procesalismo religioso, sin embargo, la celebración de los negocios procesales, especialmente atípicos, debe ir acompañada con mucho cuidado, considerando que estos no tienen reglas explícitas.

Palabras clave: Procedimiento civil; Autonomía; Negocios legales. 


\section{Introdução}

Com o advento da Lei n ${ }^{\circ}$ 13.105/2015, também conhecido como Código de Processo civil, o qual traz normativas, princípios, mecanismos e instrumentos que direcionam o operador do direito a um correto andamento ao processo, houve uma reorganização das estruturas relevantes com consideráveis alterações a este importante diploma legal.

Dentre estas modificações encontram-se alterações a base principiológica do código previstos nos artigos $1^{\circ}$ ao 12 , à tutela provisória que estão nos artigos 294 ao 311 e o processamento de recursos previstos nos artigos 994 ao 1.044 , sendo que todos estes são imprescindíveis à compreensão de como se opera a nova legislação processual.

Ainda, a vinda do referido dispositivo legal trouxe uma das principais inovações processuais, que é a possibilidade de realizar os chamados negócios jurídicos processuais, especialmente os típicos e atípicos, já praticados desde o antigo Código Civil, entretanto, melhor regulamentado, amparando as partes que queiram pactuar entre si a fim de solucionar seus conflitos livremente.

Com o cenário atual de abarrotamento dos Tribunais Superiores e a morosidade da justiça, havendo sempre altas custas que devem ser suportadas pelos litigantes e a instabilidade das decisões judiciais e ainda o gradativo crescimento das demandas, ouve uma certa preocupação do legislador com a eficácia da prestação jurisdicional, o acesso à justiça e a soluções alternativas de litígios das quais se tornam cada vez mais necessárias, a fim de garantir que o poder judiciário cumpra sua função processual de maneira efetiva, encontrando soluções jurídicas adequadas aos conflitos existentes, e ainda cumprindo as regras processuais existentes e as estabelecidas entre as partes.

Essa novidade trazida pelo Código de Processo Civil de 2015 possibilita que haja a convenção de procedimentos e estipulação de pactos procedimentais entre as partes sobre a forma de litigar, tratando sempre as peculiaridades de cada lide e estimulando a efetiva solução de conflitos, em detrimento do seguimento do processualismo religioso, considerando que o objetivo principal do poder judiciário é que a parte eu o invoque tenha seu direito como indivíduo preservado.

O objetivo do presente estudo é realizar uma análise sobre os negócios processuais típicos e atípicos, seu cabimento e regramento, a fim de entender como pode se dar cada tipo de negócio e o cuidado que as partes devem ter ao pactuá-los.

\section{Metodologia}

A metodologia empregada ao presente trabalho foi a pesquisa bibliográfica, considerando que construímos nosso texto através da análise de diversas doutrinas encontradas em livros, revistas cientificas, bibliotecas digitais, teses, pesquisas, artigos e legislação sobre o assunto. Sobre este tipo de metodologia, Medeiros aponta:

A pesquisa bibliográfica é caracterizada pela utilização de fontes secundárias, ou seja, pela identificação e análises dos dados escritos em livros, artigos de revistas, dentre outros. Sua finalidade é colocar o investigador em contato com que já se produzia a respeito do seu tema de pesquisa (Medeiros, 2000, p.40).

A escolha do tema deu-se em nossa turma de mestrado, quando realizamos uma atividade analítica acerca das mudanças ocorridas em razão da vinda do Novo Código de Processo Civil, o que despertou nosso interesse e anseio pela pesquisa.

Inicialmente realizamos uma pesquisa vasta sobre o assunto negócios processuais, especificamente no que tange as mudanças em caráter permissivo trazidas pelo Novo Código de Processo Civil, bem como a doutrina vigente, a fim de que pudéssemos obter um posicionamento concreto e tecer uma narrativa acerca de sua definição e das definições dos negócios processuais típicos e atípicos.

Posteriormente, voltamos nossa pesquisa para o regramento existente por trás da ideia de permissibilidade advinda do novo código, através da análise de diversas literaturas sobre o assunto, e por meio desta foram formadas as conclusões a respeito dos negócios processuais típicos e atípicos aqui apresentadas. Especificamente, pretendemos concluir que a vinda da legislação atual acarreta um aumento da liberdade as partes que desejam realizar um negócio processual, entretanto, há certo regramento 
que deve ser seguido a fim de preservar os direitos das partes envolvidas.

\section{Resultados e Discussão}

Os negócios jurídicos processuais surgiram com maior enfoque através do advento do Código de Processo Civil de 2015, o qual trouxe uma maior autonomia da vontade aos litigantes do processo, possibilitando as partes ajustar mudanças procedimentais, além de convencionar sobre o ônus da prova, poderes, faculdades e outros assuntos de extrema importância dentro de uma relação processual e que antes eram zelados pela legislação.

Para Romão (2015):

As mudanças advindas do Novo Código de Processo Civil trazem "uma introdução da autonomia privada dentro da esfera processual, o que denota a sagacidade do novo Código em propiciar um procedimento mais democrático e aliado as expectativas das partes, pois estas poderão adequá-lo às suas pretensões".

Para Cabral (2016) "A sistemática existente na teoria do Direito para o estudo dos atos jurídicos em geral pode ser transposta, em grande medida, para o Direito processual, já que os atos do processo são, inegavelmente, espécies de ato jurídico"

Para Azevedo (2002), negócio jurídico é "todo fato jurídico consistente em declaração de vontade, a que o ordenamento jurídico atribui os efeitos designados como queridos, respeitados os pressupostos de existência, validade e eficácia impostos pela norma jurídica que sobre ele incide"

O código tratou da temática em seu artigo 190, o qual enuncia que:

"Art. 190. Versando o processo sobre direitos que admitam autocomposição, é lícito às partes plenamente capazes estipular mudanças no procedimento para ajustá-lo às especificidades da causa e convencionar sobre os seus ônus, poderes, faculdades e deveres processuais, antes ou durante o processo.

Parágrafo único. De ofício ou a requerimento, o juiz controlará a validade das convenções previstas neste artigo, recusando-lhes aplicação somente nos casos de nulidade ou de inserção abusiva em contrato de adesão ou em que alguma parte se encontre em manifesta situação de vulnerabilidade."

A partir deste dispositivo se faz necessária inicialmente uma breve explanação do conceito de negócio jurídico, conforme virá a seguir.

Negócio jurídico constitui um pilar do direito privado, pois expressa o princípio da autonomia privada nas relações negociais.

Segundo Marinoni (2017), negócio jurídico processual: "É a declaração de vontade emitida em obediência aos seus pressupostos de existência, validade e eficácia, cujo propósito deve ser o de produzir efeitos lícitos."

A base do negócio jurídico é justificada na autonomia da vontade e é tratada como um princípio fundamental da autodeterminação do ser humano, ocorre que no direito público ele sofre limitações. E isto se aplica ao processo, pois as partes possuem limitações ao postularem a solução de um conflito com a intervenção do Estado Juiz.

Ainda há o problema de estabelecer até que ponto o juiz estará vinculado ao que é acordado pelas partes no processo, quais serão os objetos e limites destas pactuações.

Nas palavras de Araújo (2015): "O período atual deve permitir que o princípio da autonomia das partes reflita diretamente no processo para pretensões que admitam a autocomposição. Estabelecida esta primeira condição para a validade das convenções processuais, surgem inúmeros pontos decorrentes de sua admissão."

Ainda, há que se diferenciar atos processuais unilaterais de negócios jurídicos processuais unilaterais, pois há a semelhança em suas denominações que podem causar confusão, mas os mesmos são institutos diferentes cuja pratica toma caminhos distintos. 
Os atos processuais unilaterais correspondem à manifestação de apenas uma das partes no processo, e sua eficácia tem como fim cumprir com uma faculdade processual, um ônus ou ainda um dever. Já o negócio processual unilateral representa a emanação unilateral da vontade de uma das partes, que vincula todas as partes envolvidas em um processo.

Estes negócios ainda podem ser classificados em não receptícios e receptícios. O primeiro consiste em uma desistência do processo antes da citação, ocasionando poucas consequências às partes envolvidas na demanda. Já no segundo, o pedido de desistência ocorre posteriormente a citação do requerido, podendo ocasionar inúmeras consequências a parte solicitante.

O negócio jurídico se erige sobre dois requisitos principais, o da existência e o da validade.

Pois para que haja o negócio jurídico é necessário que haja uma declaração de vontade das partes, uma finalidade do negócio jurídico diretamente ligada a intenção de adquirir, modificar, conservar ou ainda extinguir direitos, inda, que haja idoneidade do objeto, e para que este pacto seja válido deve-se prezar pelos requisitos elencados no artigo 104 do Código Civil Brasileiro, a saber: "Art. 104. A validade do negócio jurídico requer: I - agente capaz; II - objeto lícito, possível, determinado ou determinável; III - forma prescrita ou não defesa em lei."

Assim as partes devem, ao celebrarem negócios processuais, observar as normas e princípios que regulam os negócios jurídicos materiais para que haja validade dos negócios processuais.

Há uma inquietação na doutrina ao discorrer sobre os limites das atribuições de poderes às partes para a celebração dos negócios processuais. Pois o objetivo do processo é a realização do direito material, que é marcado pelo poder de disposição.

Para Almeida (2014) "o acordo processual não visa solucionar o conflito, mas regulamentar, nos moldes desejados pelas partes, o próprio método de solução, isto é, o exercício da jurisdição.”

Parte da doutrina é a favor da prevalência da liberdade de formação de negócios processuais e que a plenitude da autonomia da vontade deve ser garantida sempre que possível, que sempre que haja dúvida a interpretação deve ser favorável à sua manutenção.

A doutrina denomina de supercontratos os negócios processuais que possuem natureza material e processual e tem efeitos substanciais.

Os negócios jurídicos processuais utilizam os elementos estruturais da teoria geral do negócio jurídico para a sua formação, mas a sua natureza é totalmente processual.

Assim, o negócio jurídico processual, ainda, pode ser conceituado como um fato jurídico voluntário cujo suporte fático confira ao respectivo sujeito o poder de escolher a categoria jurídica ou, ainda, estabelecer certas situações processuais.

Desta forma, é possível associar que o negócio processual é um ato pelo qual as partes dispõem sobre a matéria processual, nos limites da lei, podendo haver uma negociação.

Silva (2003), aponta que é necessário ter cuidado pois:

"A expressão negócio processual pode induzir em erro se através dela se pretende, uma vez mais, afirmar que todos os efeitos induzidos por um ato processual devem ser abrangidos pela vontade do respectivo autor. Há efeitos do ato processual negocial que continuam a ser tabelados."

Há ainda, peculiaridades sobre a capacidade das partes que deve ser tanto jurídica quanto processual em razão dos efeitos processuais produzidos no processo os quais serão imunizados pela coisa julgada.

No negócio jurídico processual a integração da vontade estatal é essencial, visto que os atos e negócios processuais podem produzir efeitos severos como a modificação da relação jurídica.

A diferença que ocorre entre estes tipos de direitos, é a de que no negócio jurídico, para que a sua formação e sua eficácia é necessário a manifestação de vontade bilateral, já que no negócio processual a sua formação será bilateral, mas sua eficácia será multilateral. 
Deste modo, os atos e os negócios processuais podem produzir efeitos substanciais de forma severa, pois com a modificação da própria relação jurídica material que foi judicializada.

O acordo de vontades que dá origem ao negócio processual prevê a integração da vontade das partes, mas a eficácia processual irá depender do controle realizado pelo juiz.

O artigo outrora mencionado, art. 190 do CPC, permite que mesmo que haja uma liberdade entre as partes para pactuarem livremente, desde que nos limites da lei, o juiz poderá recusar a validade e a eficácia do negócio jurídico processual, o que funciona como um balizador dos limites dessa autonomia da vontade das partes.

Necessária se faz a diferenciação entre o negócio processual e o negócio jurídico, considerando a importância que ambos exercem em nosso ordenamento jurídico, sendo ambos conhecidos por ser pactos realizados pelas partes sobre aspectos processuais que lhes convém, podendo tais aspectos, uma vez pactuados, ser reconhecidos como o procedimento padrão adotado ao caso, modificando totalmente o rumo de uma lide processual e de seu julgamento com relação a vários fatores, além de influenciar todas as partes envolvidas, além dos auxiliares de justiça.

Inicialmente, é notável que ambos os institutos são diferenciados desde seu nascimento, ou seja, desde sua constituição. Conforme explicita Rosenberg (2004), "o negócio processual nasce pelo acordo das partes, mas sua constituição e sua eficácia tem como território natural o processo."

Didier Jr (2018), por sua vez, conceitua o negócio processual como sendo "o fato jurídico voluntario em cujo suporte fático se reconhece ao sujeito o poder de regular, dentro dos limites fixados no próprio ordenamento jurídico, certas situações jurídicas processuais ou alterar o procedimento".

Por sua vez o negócio jurídico, nas palavras de Nogueira (2001), é o fato jurídico voluntario em cujo suporte fático, descrito em norma processual, esteja conferido ao respectivo sujeito o poder de escolher a categoria jurídica ou estabelecer, dentre os limites fixados no próprio ordenamento jurídico, certas situações jurídicas processuais.

O negócio jurídico é fruto da pactuação individual e privada das partes, sendo uma declaração de vontade das partes sobre assuntos de seus interesses dentro da esfera processual, tais como questões procedimentais, ônus da prova, questões de julgamento, prazos entre outros, a fim de produzir efeitos jurídicos que sejam benéficos a ambas as partes.

Nas palavras de Ataíde Junior (2015):

"Em outros termos, negócio jurídico processual é o ato por meio do qual as partes dispõem sobre matéria processual ou não, nos limites impostos pela norma, com reflexos no processo seja ele contemporâneo ou não a negociação. Sua aceitação, contudo, não é unanime a doutrina se divide de modo a negar ou reconhecer a existência dos negócios processuais."

Os negócios jurídicos, como todos os acordos de vontade, necessitam de certa limitação, considerando que não são todos os acordos pactuados entre as partes que podem se sobrepor a Carta Magna ou a legislação vigente, sob o risco de causar consequências tanto para as partes envolvidas, quanto para o próprio ordenamento jurídico, sendo, portanto, estabelecidas certas limitações.

Para Barreiros (2017), "a primeira parte da doutrina consagra limites genéricos, e a segunda parte descreve, por meio de diretrizes que servem de 'auxiliares metódicos', a especificidade dos limites".

Um exemplo de funcionamento dessa norma é a questão dos prazos peremptórios, sendo estes prazos importantíssimos ao desenvolvimento do feito, mesmo que pactuado entre as partes que o prazo possa ser maior, não há como dilatar estes prazos, devendo respeitar a previsão legal, inclusive sob pena de afetar a garantia de duração razoável do processo prevista em nossa Constituição Federal, em seu artigo 5, inciso LXXVIII.

Cabe ao julgador zelar pelo funcionamento efetivo do processo, sendo dele a manifestação contrária ao pacto realizado entre as partes para dilações dos prazos processuais, a fim de resguardar a ordem processual e preservar o procedimento em si. 
Ademais, em qualquer situação em que a parte se encontre em algum grau de vulnerabilidade, pode o julgador manifestar-se pela não efetivação da pactuação privada entre as partes, funcionando a lei neste aspecto como protetor dos direitos fundamentais individuais e da dignidade da pessoa humana dentro da esfera processual.

Por sua vez, o próprio objeto da negociação, além do cumprimento dos requisitos de validade expressos no artigo 190 são capazes de gerar limitações ao ato de pactuar.

Dessa forma, pode-se concluir que os negócios processuais são limitados principalmente pelos princípios fundamentais constitucionais, considerando que o principal objetivo de qualquer demanda judicial é ver a solução do conflito que ensejou a busca pelo sistema judiciário, da melhor maneira possível, servindo a lei como fonte reguladora em defesa da aplicação destes princípios, impedindo que as partes pactuem a respeito de assuntos que venham a lhe causar alguma consequência negativa.

O presente trabalho versa sobre a liberdade de pactuação e livre iniciativa concedida as partes com a advinda do Novo Código de Processo Civil. Mas apesar deste panorama liberal existe a figura do julgador e dos demais auxiliares de justiça, que não perdem nenhuma de suas funções em decorrência da nova legislação.

Para Godinho Renaut (2015) "a autonomia das partes deve ser analisada dentro de uma perspectiva constitucional e de uma teoria dos direitos fundamentais que autoriza e ao mesmo tempo impõe limites às manifestações de vontade"

O juiz é na relação processual, além do julgador, o regulamentador quanto a validade dos atos processuais, ou homologador de qualquer negócio que venha a ser feito entre as partes de uma relação negocial, cabendo a ele ainda a função de analisar se as partes que estão a litigar são capazes, se o objeto de uma demanda é viável, as questões de foro processual, a fundamentação, além do preenchimento de vários outros requisitos importantes para o bem correr de uma demanda.

Com relação aos negócios jurídicos, o juiz atual como uma espécie de filtro que verifica se o negócio pactuado entre as partes possui certa validade processual e procedimental, se está dentro dos limites constitucionais, se fere alguma premissa estabelecida em nossa Carta Magma, se é pautado em legislação pré-existente, se corresponde aos princípios da legalidade, da segurança jurídica, se o negócio pode ser abusivo para uma das partes, causando consequências irreparáveis.

Nas palavras de Ponte (2015) "a natureza da demanda pode exigir a acolhida de tutelas processuais peculiares, bem como a pratica de atos processuais específicos, cuja forma e tempo não possuem antecedentes normativos dentro da legislação".

Cabe ao julgador sopesar estas medidas tomadas pelas partes, uma vez que peculiares em geral, e verificar se atendem as necessidades do caso em analise, sopesando ainda se a aplicação de determinadas medidas acarretará serias consequências ao funcionamento processual, ou a alguma das partes envolvidas, a fim de satisfazer inteira justiça quando da aplicação dos institutos jurídicos.

Desta forma, percebe-se a importância plena do julgador uma vez estipulados negócios jurídicos, ressaltando-se que, uma vez pactuado um negócio processual, típico ou atípico, este exerce influência inclusive sobre o próprio julgador, que deve passar a adotar aquele procedimento no julgamento deste caso, além de todos os auxiliares de justiça.

Os negócios processuais são divididos em típicos e atípicos, de acordo com sua regulamentação.

Para Theodoro Jr. (2016) "negócios jurídicos processuais são um autorregramento da vontade significa o poder de escolha da categoria jurídica ou das situações jurídicas que configurarão sua eficácia”.

Os negócios processuais típicos levam este nome pois já existem na legislação, ou seja, já são regulamentados pela legislação vigente, de forma que as partes, ao adotarem algum procedimento desta natureza, não tem a necessidade de lutar para que o negócio seja valido ou que seja aceito por todos os envolvidos e homologado pelo julgador.

Para Cunha (2014), estes negócios jurídicos são "produto da autonomia privada ou da autorregulação de interesses, implicando liberdade de celebração e de estipulação. Isso não impede que a legislação fixe o regime de determinados negócios" Os negócios processuais típicos estão presentes em todo o código de processo civil.

Para Tartuce (2015): "Este tipo de negócio versa sobre toda a ação humana, de autonomia privadas, com a qual os 
particulares regulam por si os próprios interesses, havendo uma composição de vontades, cujo conteúdo deve ser lícito".

O calendário processual é um exemplo de negócio processual típico, consistindo na adoção de prazos específicos pactuados pelas partes para um determinado feito, objetivando a busca pela otimização processual e maior efetividade ao julgamento, sendo que, uma vez adotado, os prazos que devem ser obedecidos por todos dentro da relação processual são os estabelecidos, vinculando todas as partes.

Além disso, é dispensada a intimação das partes, considerando que, uma vez programado um calendário, todos já estão cientes quanto aos prazos para cada ato processual, demonstrando a celeridade processual ocasionada pela adoção deste instituto jurídico, podendo inclusive ser determinada coerção e multa, com a fixação de astreintes para os casos em que não seja respeitado este calendário pelas partes.

Por sua vez existe ainda a suspensão processual, ocorrendo que não as partes acordarem livremente por uma suspensão em decorrência de diversos motivos, como por exemplo, para que possam compactuar extrajudicialmente, ou quando haja a ausência de provas materiais sobre os fatos alegados por ambas as partes.

Logicamente, esta suspensão não pode ocorrer a todo tempo e possui prazo máximo fixado para ocorrer, sendo este de 01 (um) ano, podendo ser repetido por mais um ano, e não mais do que isso, sob pena de atrasar o devido andamento processual e acarretar consequências as partes.

Ainda, a convenção sobre prazos, como por exemplo a renúncia de prazos, que pode se dar de forma expressa ou tácita, além da fixação de prazos dilatórios, ou seja, aumento de prazo para a apresentação de determinados atos processuais, entretanto, as partes podem apenas convencionar sobre prazos peremptórios, ou seja, prazos cuja ausência pode resultar em consequências processuais, a fim de diminui-los, nunca aumenta-los, considerando a importância deste tipo de prazos para o andamento processual regular, podendo apenas o julgador vir a aumentar os prazos peremptórios em situações extremas e de extrema necessidade, sob pena de retardar indevidamente o processo.

Ademais, existem ainda os negócios processuais atípicos, nascidos após advindo o artigo 190 do Novo Código de Processo Civil, que versa que:

Art. 190. Versando o processo sobre direitos que admitam autocomposição, é lícito às partes plenamente capazes estipular mudanças no procedimento para ajustá-lo às especificidades da causa e convencionar sobre os seus ônus, poderes, faculdades e deveres processuais, antes ou durante o processo.

Parágrafo único. De ofício ou a requerimento, o juiz controlará a validade das convenções previstas neste artigo, recusando-lhes aplicação somente nos casos de nulidade ou de inserção abusiva em contrato de adesão ou em que alguma parte se encontre em manifesta situação de vulnerabilidade.

A premissa estabelecida pela nova regra de livre iniciativa acompanha o pensamento do nosso ordenamento jurídico atual, no sentido de liberar espaço para que as partes possam livremente pensar, optar pelo que melhor lhes convier, sendo que a atipicidade, conforme nomenclatura, deriva desta criação de um negócio processual que anteriormente não existia em nosso sistema processual e judiciário, caracterizando uma inovação.

A questão mais interessante no que condiz aos negócios processuais atípicos, e inclusive maior comentada pela doutrina, havendo inúmeras divergências quanto a sua aceitação, é a aplicação do "pacto de non petendo", o que, brevemente, seria uma clausula que versa que as partes deixariam ou abririam mão de versar sobre determinado direito em decorrência de este assunto já ter sido tratado e resolvido de maneira extrajudicial.

Ou seja, a parte assinaria um acordo privando a si mesma de litigar com relação a um determinado tema, sob o argumento de que aquele assunto já estaria resolvido de maneira privada entre as partes.

Tal assunto, apesar de esbarrar no direito de ação, sob a premissa de que ninguém seria impedido de realizar seu direito de ingresso ao poder judiciário independente do que tenha convencionado individualmente, sob pena de falecimento do direito 
de ação, nada mais é que uma renúncia a este direito, ou a simples colocação em pratica do defendido pelo artigo 190, ou seja, as partes, da mesma forma que soa livres para convencionar entre si, estariam livres para optar pelo que podem ou não lutar futuramente por meio do judiciário.

O direito de ação previsto constitucionalmente no artigo 5, inciso XXXV não seria lesionado, e apesar do assunto ser polemico, deve ser encarado como uma pratica da livre iniciativa e convenção entre as partes, conforme o que foi defendido neste trabalho desde o início.

Nas palavras de Araújo (2016) "O pacto de non petendo não elimina propriamente o direito de ação, mas apenas impede a judicialização de determinada pretensão. Com o pacto não há morte do direito material, apenas a sancionabilidade”.

É claro que, como em todo instituto, haveriam regras a serem seguidas para a execução de um pacto neste sentido, principalmente devendo seguir à risca as regras do artigo 190, especificamente no que tange a capacidade processual, bem como que o pacto seja especificado a fim de não passar despercebido em um contrato privado. Toda cautela é necessária a fim de não causar maiores consequências as partes.

Há ainda a formação de negócios processuais executivos, que dizem respeito a contratos ou pactos celebrados em sede de processo de conhecimento, a fim de formar um título executivo, havendo neste caso maiores privações á pratica, considerando que a formação de título executivo não é assunto simples e nem pode ser dada a qualquer indivíduo.

\section{Considerações Finais}

Com base nos fatos acima explicitados podemos concluir que a vinda do Novo Código de Processo Civil trouxe inúmeras mudanças processuais, especificamente no que tange aos negócios processuais, dentre eles os típicos e atípicos, versando em seu artigo 190 sobre a possibilidade de as partes, desde que maiores e capazes, pactuarem entre si livremente e a qualquer momento do feito, sendo antes ou depois da citação, sobre o procedimento a ser adotado na demanda, além do ônus da prova, poderes, faculdades, dentre outros assuntos importantes na relação processual.

A vinda destas mudanças tem como fundamento o princípio da livre iniciativa processual, e qualquer ato pactuado vincula todas as partes, inclusive o julgador, que deve ser previamente consultado, e os auxiliares de justiça, funcionando literalmente como um novo procedimento a ser adotado dentro da relação processual, numa tentativa de melhor solucionar os conflitos existentes dentro de uma demanda, primando pela eficácia processual e pela plena e justa solução da lide, em detrimento do processualismo exacerbado.

Entretanto, esta livre pactuação deve estar pautada nos princípios constitucionais e ser homologada pelo julgador para que possa produzir efeitos, considerando que há certos limites que devem ser empregados, como em todos os institutos previstos em nosso ordenamento jurídico, cabendo ao julgador estabelecer os parâmetros entre cada negócio jurídico praticado, e realizar a verificação das consequências, dos efeitos e da obediência ao direito processual pré-existente e a carta magma antes que qualquer acordo seja realizado, a fim de garantir que nenhuma parte seja lesionada pela iniciativa privada de escolha procedimental, buscando uma efetiva solução do conflito inicial.

Nos negócios processuais típicos, que já estão pautados e regulamentados em lei, não há essa extrema necessidade de aceitação de um negócio uma vez pactuado.

Diferente do que ocorre com os negócios atípicos, que, conforme a própria nomenclatura menciona, não encontram previsão legal, necessitando desta pré-análise de validade para que possam ser homologados e passar a produzir seus efeitos jurídicos, possibilitando as partes optar pelas questões procedimentais e de cunho pessoal.

Para trabalhos futuros, deve ser observado o regramento existente sobre os negócios jurídicos, bem como os princípios constitucionais, a fim de de que o negócio seja celebrado de forma que a liberdade concedida às partes com a vinda do novo código não seja motivo de lesão de direitos. 
Research, Society and Development, v. 10, n. 14, e124101421649, 2021

(CC BY 4.0) | ISSN 2525-3409 | DOI: http://dx.doi.org/10.33448/rsd-v10i14.21649

\section{Referências}

Almeida, D. A. R. (2014). Das convenções processuais no processo civil. Tese de Doutorado em Direito. Rio de Janeiro: Faculdade de Direito da Universidade do Estado do Rio de Janeiro.

Araújo, F. C. (2016). Curso de Processo Civil: parte geral. Malheiros.

Ataíde Junior, J. R. (2015). Negócios Jurídicos Materiais e Processuais - existência, validade e eficácia - Campo- Invariável e campos dependentes: sobre os limites dos negócios jurídicos processuais. Revista de Processo: Revista dos Tibunais.40 (244). $393-423$.

Azevedo, A. J. (2002). Negócio Jurídico: existência, validade e eficácia. Saraiva.

Barreiros, L. M. S. (2017). Convenções Processuais e Poder Público. Juspodivm.

Brasil. 1973. LEI N 5.869. Código de Processo Civil. Diário Oficial da República do Brasil.

Brasil. 1988. Constituição Federal da República Federativa do Brasil. Diário Oficial da República do Brasil. Brasília, DF.

Brasil. 2015. Código de Processo Civil. Diário Oficial da República do Brasil.

Cabral, A. P. (2016). Convenções Processuais. Juspodivm.

Cunha, L. C. (2014). Negócios Jurídicos processuais no processo civil brasileiro. http://www.academia.edu/10270224/Neg\%C3\%B3cio s_jur\%C3\%ADdico s_processuais_no_processo_civil_brasileiro

Didier JR., F. (2018). Curso de Direito Processual Civil: parte geral e processo de conhecimento. JusPodivm.

Godinho, R. R. (2016). A possibilidade de negócios processuais atípicos em matéria probatória. Revista dos Tribunais.

Marinoni, L. G., Arenhart, S. C. \& Mitidiero, D. (2015). Novo Código de Processo Civil Comentado. Revistas dos Tribunais.

Medeiros. J. B. (2000). Redação cientifica: A prática de fichamentos, resumos e resenhas. (4a ed.), Atlas.

Nogueira, P. H. P. (2001). Negócios Jurídicos Processuais: Análise dos provimentos judiciais como atos negociais. Salvador, BA: Tese de Doutorado da UFBA. Bahia, Brasil.

Ponte, M. D. \& Romão, P. F. (2015). Negócio Jurídico Processual e flexibilização do procedimento: As influências da autonomia privada no paradigma publicista do Direito Processual Civil. Revista Eletronica de Direito Processual, 16 (16). 305-334.

Rosenberg, L., Gottwald, P. \& Schwab, K. H. (2004). Zivilprozessrecht. C.H. Beck’schle Verlagsbushlandlung.

Silva, P. C. (2003). Acto e Processo - O Dogma da Irrelevância da Vontade na Interpretação e nos Vícios do Acto Postulativo. Coimbra, PT.

Tartuce, F. (2015). Direito civil 1. Lei de Introdução e Parte Geral. Editora Método.

Theodoro Júnior, H., Nunes, D., Bahia, A. M. F. \& Pedron, F. Q. (2016). Novo cpc: fundamentos e sistematização. Forense. 